\title{
Relapse rate and long-term management of plaque psoriasis after treatment with photochemotherapy and dithranol
}

\author{
D VELLA BRIFFA， M W GREAVES，A P WARIN， S ROGERS，J MARKS， S SHUSTER
}

\begin{abstract}
The relapse rate of plaque psoriasis after initial clearing with the "Ingram" dithranol regimen or photochemotherapy was comparable when no maintenance treatment was given. It was estimated that psoriasis recurs to half of its pretreatment extent after about six months in half the patients. Maintenance treatment with photochemotherapy once a week or once every three weeks was useful in reducing the relapse rate. This study failed to show any statistical difference in relapse rates between these two maintenance schedules. If this finding turns out to be true over longer periods of study the maintenance schedule entailing treatment once every three weeks with its lower cumulative dose of long-wave ultraviolet light will clearly be preferable. The psoriasis in most patients was under better overall control with maintenance treatment than with intermittant clearing courses given when the extent of the psoriasis had become unacceptable to them. There was, however, a group of roughly one-fifth of patients who remained in satisfactory remission for over 16 months after initial clearing. Regular maintenance treatment was unnecessary in them.
\end{abstract}

Much more information is needed on response to treatment in subgroups of patients to permit recognition from the start of which patients are likely to have long remission and which are not.

Institute of Dermatology, Homerton Grove, London E9 6B X

D VELLA BRIFFA, MD, research associate

$M$ W GREAVES, PHD, FRCP, professor of dermatology

A P WARIN, MB, MRCP, tutor in dermatology (present address: Royal Devon and Exeter Hospital (Wonford), Exeter EX2 5DW)

Department of Dermatology, Royal Victoria Infirmary, Newcastle upon Tyne NE1 4LP

S ROGERS, MRCP, MRCPI, consultant dermatologist (present address : City of Dublin Skin and Cancer Hospital, Dublin 2)

J MARKS, DM, FRCP, consultant dermatologist

S SHUSTER, PHD, FRCP, professor of dermatology

\section{Introduction}

We have shown that outpatient treatment with photochemotherapy (8-methoxypsoralen (methoxsalen) and long-wave ultraviolet light; PUVA) and an inpatient dithranol regimen were comparable in their initial clearing of chronic plaque psoriasis. Though PUVA took longer than dithranol to clear the rash it had certain advantages, including greater cost effectiveness and patient acceptability. In psoriasis, however, the initial clearing is only one aspect of treatment, for recurrence sooner or later after stopping treatment is usual. We have therefore extended our trial and compared the relapse rate after PUVA with that after dithranol; we have also compared two PUVA "maintenance" regimens for their ability to prevent or postpone relapse. With these additional facts we can make more rational decisions about how best to use PUVA in the long-term management of psoriasis. Because of possible toxicity of the treatment it is clearly desirable that the lowest UVA exposure compatible with reasonable continuity in clinical response should be used.

\section{Patients and methods}

The trial was carried out in two centres, as before. ${ }^{1}$ Relapse rate after clearing with PUVA was first compared with that after clearing with dithranol: subsequently these were compared with relapse rates in patients receiving two different PUVA maintenance regimens, and the two maintenance regimens were compared with one another. In all these studies relapse was arbitrarily defined as recurrence of the plaque psoriasis affecting $50 \%$ or more of the body area that had been affected before the clearing regimen started. As previously, scalp and flexural psoriasis were not taken into account in estimating the affected area.

\section{RELAPSE RATE WITHOUT MAINTENANCE: DITHRANOL VERSUS PUVA}

Dithranol-Seventy-six patients whose psoriasis had been successfully cleared by the dithranol regimen in the previous trial took part. Details of treatment with dithranol paste, tar baths, and ultraviolet B light are described elsewhere. ${ }^{1}$ The mean age of the patients was 41.1 years ( $\pm 1.5 \mathrm{SEM})$, the male to female ratio was $1.8: 1$, the rash 
had been present for a mean of 17.5 years $(+1.3$ SEM), and the mean body area affected at the start of treatment had been $27 \%$ $( \pm 2$ SEM). Once the psoriasis was cleared no treatment was allowed apart from emulsifying ointment $(B P)$ and aqueous cream $(B P)$ At each follow-up visit the percentage of the body area affected with plaque psoriasis was assessed by Wallace's Rule of Nines and recurrence of the rash expressed as a percentage of the body area affected before the initial clearance treatment.

PUVA-A new cohort of 53 patients who had been successfully cleared with PUVA were entered sequentially into this part of the study. Details of treatment schedules with oral 8-methoxypsoralen and UVA are described elsewhere. ${ }^{1}$ The mean age was 36.6 years $( \pm 1.7 \mathrm{SEM})$, the male to female ratio was $1.5: 1$, the rash had been present for a mean of 16.5 years $( \pm 1.3 \mathrm{SEM})$, and the mean body area affected at the start of treatment had been $30 \%( \pm 3$ SEM $)$ The follow-up procedure was as for the group of patients cleared with dithranol.

RELAPSE RATE IN PATIENTS CLEARED WITH PUVA AND THEN GIVEN MAINTENANCE PUVA

One hundred and twelve patients were entered sequentially into this part of the study immediately after their rash had been cleared with PUVA. They were randomly divided into two groups. The first group of 54 received PUVA treatments once a week. Their mean age was 37.6 years $(+1.9 \mathrm{SEM})$, the male to female ratio was $1 \cdot 3: 1$, the rash had been present for a mean of $17 \cdot 1$ years $( \pm 1 \cdot 4$ SEM), and the mean body area affected before the clearing treatment had started was $25 \%(+3$ SEM). The second group of 58 received PUVA once every three weeks. Their mean age was $36 \cdot 7$ years $( \pm 1 \cdot 4$ SEM $)$, the male to female ratio was $1 \cdot 1: 1$, the rash had been present for 17.4 years $(+1.6$ SEM $)$, and the mean body area affected before the clearing treatment had started had been $26 \%( \pm 2$ SEM).

Response to photochemotherapy of 165 patients during initial clearing phase. Figures are means $\pm S E M$

\begin{tabular}{|c|c|c|c|c|}
\hline \multirow[b]{2}{*}{ Allocation } & & \multirow{2}{*}{$\stackrel{\text { No }}{\text { maintenance }}$} & \multicolumn{2}{|c|}{ Maintenance } \\
\hline & & & $\begin{array}{l}\text { Once a } \\
\text { week }\end{array}$ & $\begin{array}{c}\text { Once every } 3 \\
\text { weeks }\end{array}$ \\
\hline $\begin{array}{l}\text { No of patients } \\
\text { Initial UVA dose }\left(j \mathrm{~J} / \mathrm{cm}^{2}\right)\end{array}$. & $\begin{array}{l}\ldots \\
\because \\
\because \\
\cdots\end{array}$ & $\begin{array}{c}53 \\
2 \cdot 8 \pm 0 \cdot 1 \\
16 \pm 1 \\
41 \pm 3 \\
7 \cdot 0 \pm 0 \cdot 7 \\
88 \cdot 0 \pm 11 \cdot 6\end{array}$ & $\begin{array}{c}54 \\
2 \cdot 7 \pm 0 \cdot 1 \\
19 \pm 1 \\
46 \pm 2 \\
7 \cdot 4 \pm 0 \cdot 6 \\
102 \cdot 3 \pm 10 \cdot 4\end{array}$ & $\begin{array}{c}58 \\
2 \cdot 9 \pm 0 \cdot 4 \\
21 \pm 1 \\
51 \pm 3 \\
8 \cdot 3 \pm 0 \cdot 6 \\
120 \cdot 6 \pm 11 \cdot 9\end{array}$ \\
\hline
\end{tabular}

The table summarises the response to PUVA during the clearing phase of the 165 patients who received this treatment.

Comparison of cumulative doses of UVA-To compare the cumulative dose of UVA under the two maintenance treatment schedules the sum of the UVA doses received by all the patients in each group was divided by the sum of the number of months of follow-up. The UVA doses given during the initial clearing phase, which were comparable in the two groups, were not included in the reckoning.

\section{Results}

DITHRANOL REGIMEN; NO MAINTENANCE TREATMENT

The 76 patients in this group were followed up for 1 to 16 months (mean 6.3 months, \pm 0.4 SEM). During this period 56 patients (74\%) relapsed in a mean of 5.4 months $( \pm 0.4$ SEM). The 20 patients who did not relapse were followed up for 4 to 16 months (mean 8.8 months, \pm 1.0 SEM). The estimated probability of remaining in clinical remission was calculated by the survivorship table method $^{2}$; figure 1 plots the result as a function of months elapsed since clearing. The shaded area represents the $95 \%$ confidence limits of these estimates. This well-established statistical approach was necessary since not all the patients were followed to the point of relapse, and the patients who were still in remission when the study was terminated were followed for variable lengths of time. Figure 1 shows that the estimated probability of remaining in remission decreased rapidly with time in this group of patients. An estimated $50 \%$ chance of relapsing was observed at 5.5 months. Later the curve flattened, however, and the estimated probability of remaining in remission was about $13 \%$ at the end of 16 months.

\section{PHOTOCHEMOTHERAPY: NO MAINTENANCE TREATMENT}

The 53 patients in this group were followed up for 1 to 16 months (mean 7.8 months, $\pm 0.5 \mathrm{SEM}$ ). During this period 37 patients $(70 \%)$ relapsed in a mean of 6.3 months $(+0.4$ SEM). The 16 patients who did not relapse were followed up for 8 to 16 months (mean 11.3 months, $\pm 0.8 \mathrm{SEM})$. As in the dithranol-treated patients the estimated probability of remaining in remission declined rapidly with time (fig 1). A $50 \%$ chance of relapsing was observed at 6.3 months, and the estimated probability of remaining in remission was still about $20 \%$ at the end of 16 months. The $95 \%$ confidence limits of the estimated probability of remaining in remission in this group of patients overlapped those in the dithranol-treated group throughout the entire follow-up period.
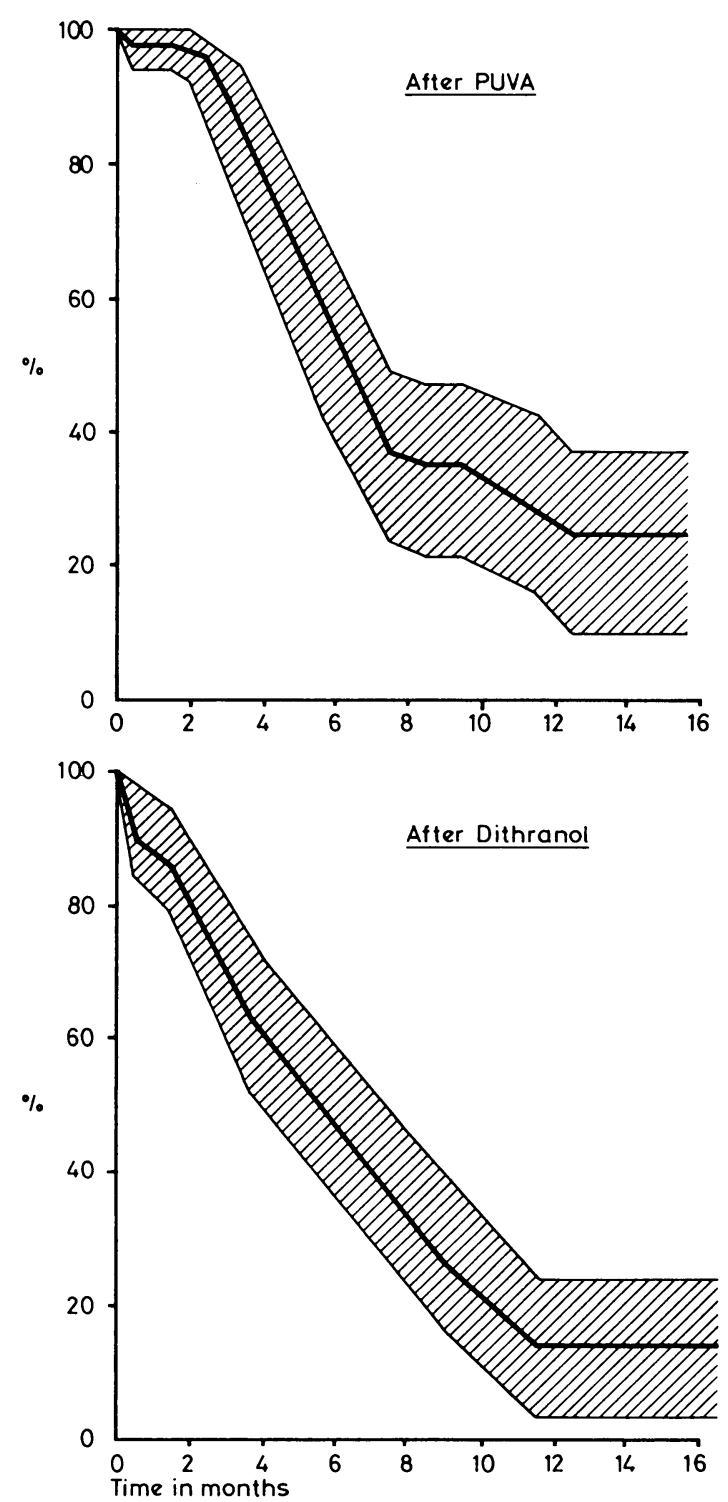

FIG 1-Estimated probability of remission (plus $95 \%$ confidence limits) after initial clearing with PUVA or dithranol when no maintenance treatment was given. Studies not concurrent.

\section{PHOTOCHEMOTHERAPY FOLLOWED BY MAINTENANCE TREATMENT}

The 54 patients allocated to maintenance treatment once a week were followed up for 1 to 16 months (mean 10.9 months, \pm 0.5 SEM) During this period eight patients $(15 \%)$ relapsed in a mean of 6.3 months $( \pm 1 \cdot 2 \mathrm{SEM})$. The 46 patients who did not relapse were followed up for 4 to 16 months (mean 11.7 months, \pm 0.5 SEM). Figure 2 shows that the estimated probability of remaining in remission was much greater than in the groups of patients not given maintenance treatment, and at the end of 16 months it was about $80 \%$. 
The 58 patients allocated to maintenance treatment once every three weeks were followed up for 1 to 16 months (mean $10 \cdot 1$ months, $\pm 0.6 \mathrm{SEM})$. During this period 15 patients $(26 \%)$ relapsed in a mean of 7.2 months ( \pm 1.0 SEM). The 43 patients who did not relapse were followed up for 3 to 16 months (mean 11.0 months, $\pm 0.6 \mathrm{SEM}$ ). Though the percentage of patients who relapsed while receiving maintenance treatment once every three weeks was 1.7 times that in the group of patients who received weekly maintenance treatment, this difference was not significant $\left(p>0.1 ; \chi^{2}\right.$ test). The estimated probability of remaining in remission in this group of patients declined more rapidly with time than in the group of patients who received weekly maintenance treatment, and at the end of 16 months it was about $70 \%$ (fig 2). Nevertheless, the $95 \%$ confidence

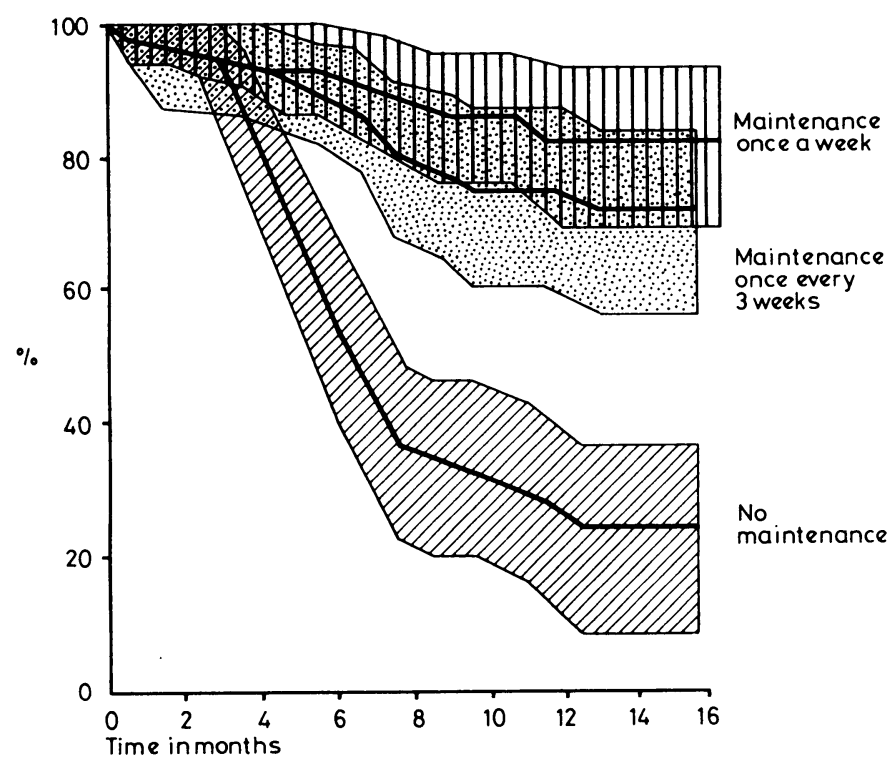

FIG 2-Influence of two different maintenance treatment schedules on estimated probability of remission after initial clearing with PUVA. "Maintenance treatment" data and "no-maintenance treatment" data collected in two separate studies.

limits of the estimates in the two groups of patients who received maintenance treatment overlapped throughout the observation period. The small difference observed between the two groups was not statistically significant and was unlikely to be clinically important.

Cumulative dose of $U V A$-The cumulative dose of UVA during maintenance treatment once a week was $2 \cdot 2$ times that in the group of patients receiving maintenance treatment once every three weeks (once a week, $27.9 \mathrm{~J} / \mathrm{cm}^{2} /$ month; once every three weeks, $12.6 \mathrm{~J} / \mathrm{cm}^{2} /$ month). This departure from the expected ratio of $3: 1$ was due at least in part to the effect of defaulting, which was more frequent in the group of patients receiving weekly maintenance treatment. The total number of exposures actually received by that group was $16 \%$ less than that expected for the total number of months for which the patients were followed. By comparison, the total number of exposures received by the group of patients on maintenance treatment once every three weeks was only $6 \%$ less than that expected for the total number of months for which this group of patients was followed. Nevertheless, absenteeism was spread evenly among the patients over a considerable number of months, and relapse of psoriasis could not be directly attributed to the effect of defaulting in any individual patients.

\section{Discussion}

The "Ingram" dithranol regimen is still the mainstay of treatment for widespread plaque psoriasis in most British dermatology clinics, since decades of experience have shown that it is both effective and relatively free of undesirable longterm side effects. Some centres provide an outpatient service, and simplified regimens have been developed for domiciliary use. $^{3}$ Many patients fail to comply with such treatment, however, since it is time consuming and inconvenient to use on a regular basis. The long-term management of severe plaque psoriasis with dithranol therefore usually consists in intermittent courses of clearance treatment on an inpatient basis. The data presented in the first part of this study show that although this may be a very satisfactory method for some patients, most patients with severe disease would need two and sometimes more clearance treatments every year. The data presented in the second part of this study indicate that the relapse rate of plaque psoriasis after initial clearance with photochemotherapy is comparable if no maintenance treatment is given, so that these patients too are likely to need two or more clearing courses in a year to keep their skin in a reasonable state. Though photochemotherapy is more acceptable to the patients, the long-term management of psoriasis with intermittent courses of photochemotherapy is also an unsatisfactory solution to the problem except for a minority of patients.

The data presented in the final part of our study indicate that psoriasis relapses in some patients despite maintenance treatment with photochemotherapy but that such maintenance treatment is effective in preventing a relapse in most patients, at least over the first year. The efficacy of weekly maintenance treatment and that of once every three weeks seems comparable in this respect. Nevertheless, the cumulate dose of UVA is much less if maintenance treatment is given only once every three weeks. Probably the total number of exposures and cumulative dose of UVA received will be two important variables influencing the incidence of undesirable long-term side effects of this treatment, including cancer of the skin. It would therefore seem more appropriate to use the less frequent maintenance treatment schedule if the use of maintenance treatment appears justified in an individual patient.

In most patients psoriasis is kept under better control if maintenance treatment is given once every three weeks than if the disease is managed with intermittent clearance courses of photochemotherapy with no maintenance treatment in-between. In addition, we have shown that the use of maintenance treatment does not seem to prejudice the eventual outcome to a second course of clearance treatment with photochemotherapy should this need arise. For instance, in a study of 33 patients we found that in a second clearing course after maintenance treatment the time to clear and the total dose of UVA needed for this were not significantly different from those in the first clearing course. It is rather difficult to compare the cumulative dose of UVA in patients who have several clearing courses and those who are given maintenance treatment. Our data suggest that the average total dose of UVA received per clearance course of treatment is roughly equivalent to the average total dose of UVA received by a patient on maintenance treatment once every three weeks over a period of eight months (excluding the doses received during the initial clearing phase). Up to $70 \%$ of patients not receiving maintenance treatment would have relapsed by that stage compared with $20 \%$ receiving maintenance treatment (fig 2). The dose of UVA would therefore accumulate less rapidly in many patients on maintenance treatment, particularly in those who are receiving it only once every three weeks. In addition, the total number of hospital visits required every year would be reduced.

Further evaluation of the long-term risks of photochemotherapy including that based on our own arrangement for follow-up of our trial patients will undoubtedly prove just as important as the evaluation of its clinical efficacy in deciding on the ultimate role of this treatment in the long-term management of psoriasis. In view of these potential hazards, which may take many years to become manifest, it is probably reasonable to reserve photochemotherapy as a first-time treatment for the more elderly patients and those with severe psoriasis-especially if they have failed to respond satisfactorily to an adequate inpatient course of dithranol-and for those patients who require more than two hospital admissions every year. Another reasonable use, even in younger patients, is as an alternative to systemic cytotoxic treatment. The information in our previous report and in this one can now serve as a basis 
from which to make decisions concerning the best way of using PUVA in those who are considered suitable for this form of treatment.

This study was sponsored by the Medical Research Council. We thank especially the working group of the MRC for their constant help and advice. The 8-methoxypsoralen (methoxsalen) tablets were donated by Stiefel Laboratories (UK) Ltd. We also thank Professor G Rose and Dr M Corbett for statistical advice, S Roubo, P Elliot, A Whiteley, and P Lamb for nursing help, and M Smith and N Vella Briffa for secretarial work.

\section{References}

${ }^{1}$ Rogers S, Greaves M, Marks J, Shuster S, Vella Briffa D, Warin A. Comparison of photochemotherapy and dithranol in the treatment of chronic plaque psoriasis. Lancet $1979 ; \mathrm{i}: 455-8$.

2 Colton T. Longitudinal studies and the use of the life table. In: Statistics in medicine. Boston, Massachusetts: Little, Brown and Co (Inc), 1974:237-50.

${ }^{3}$ Seville RH. Simplified dithranol treatment for psoriasis. $\mathrm{Br} \mathcal{F}$ Dermatol $1975 ; 93: 205 \div 8$.

(Accepted 18 December 1980)

\title{
Algorithmic method for assessing urinary incontinence in elderly women
}

\author{
P HILTON, S L STANTON
}

\begin{abstract}
In young patients the assessment of urinary incontinence is based increasingly on the results of complex urodynamic investigations. The value of such techniques in the elderly, however, is as yet unproved. Based on the clinical and urodynamic findings in 100 incontinent elderly women an algorithmic method for managing such patients was devised. A retrospective study comparing the algorithmic outcome with the results of standard urodynamic assessment showed that $60 \%$ of invasive investigations could be avoided by this method with minimal loss of diagnostic accuracy.
\end{abstract}

\section{Introduction}

The incidence of urinary incontinence in the elderly has been assessed as between $1.6 \%$ and $42 \%,{ }^{1}$ and its costs to the individual and to the Health Service are considerable. Wholesale investigation of urinary incontinence, however, is justified only if it can be shown to provide at minimal risk an accurate diagnosis which could not be obtained by simpler means; and if based on that diagnosis a rational and effective treatment could be provided. Urodynamic investigations undoubtedly provide an accurate diagnosis in young patients, though their application to the elderly is rarely reported. That effective treatment is available for correctly diagnosed urinary incontinence in the elderly is questionable. Nevertheless, in cases of incompetence of the urethral sphincter (genuine stress incontinence) Stanton and Cardozo $^{2}$ reported cures in $75 \%$ of patients over 65 years of age who were treated by colposuspension.

The risks from urodynamic investigation are small; Walter and Vejlsgaard ${ }^{3}$ reported urinary infection in only $2 \%$ of patients after investigation. Of perhaps greater importance is the discomfort and distress caused to some patients, which may be considerable in the elderly, particularly those with other

Urodynamic Unit, Department of Obstetrics and Gynaecology, St George's Hospital Medical School, London SW17 ORE

P HILTON, MB, MRCOG, clinical research fellow

St George's Hospital Medical School, London SW17 ORE

S L STANTON, FRCS, MRCOG, honorary senior lecturer physical disease or intellectual impairment. With these factors in mind we proposed to define a more efficient method of investigating urinary incontinence in elderly women.

\section{Patients and methods}

We studied 100 women aged $65-93$ years (mean $74 \cdot 6$ years) who were referred to the urodynamic unit for urinary incontinence. They were investigated according to our usual practice. On referral a standardised data sheet including general medical, neurological, gynaecological, and urological history and examination was completed. ${ }^{4}$ Peak urine flow rate was determined using either a rotating disc flow meter or a modified von Garrelts apparatus. Detrusor function was investigated by twin-channel subtracted water cystometry at a rapid filling rate (roughly $100 \mathrm{ml} / \mathrm{min}$ ) in the supine position. The effect of passive postural change on detrusor pressure was assessed and simultaneous voiding pressures and flow rates recorded where practicable (56 patients). In 30 patients whose general condition was considered to be adequate videocystourethrography was performed in place of cystometry. Urethral closure pressure profile measurements were recorded using a dual sensor microtransducer catheter ${ }^{5}$ in 22 patients. In one patient whose incontinence was not confirmed by the above procedures a Urilos nappy test ${ }^{6}$ was performed.

On completion of these investigations a diagnosis was made for each patient. Where mixed diagnoses were considered-for example, difficulty in voiding owing to outflow obstruction associated with detrusor instability - the patient was assigned to the diagnosis that warranted primary treatment.

Methods, definitions, and units conform to the standards proposed by the International Continence Society. ${ }^{10}$ Frequency is the passage of urine two-hourly or seven times or more during waking hours, and nocturia the arousal from sleep to void on two or more occasions each night.

\section{Results}

Table I lists the final diagnoses in the 100 women, established on the basis of clinical and urodynamic assessments. Table II gives the symptoms in relation to these diagnoses. Though stress incontinence was common in women with an incompetent urethral sphincter $(63 \%)$ and less common in those with detrusor instability (33\%), this symptom was also noted by $49 \%$ of the group as a whole and $77 \%$ of women with voiding difficulties. Symptoms usually associated with detrusor instability in younger patients-urgency, urge incontinence, enuresis, and both diurnal and nocturnal frequency - were common in all diagnostic categories. Of the symptoms associated with voiding difficulties, poor urinary stream had the best 